\title{
Acute Hypoxia Increases S100 $\beta$ Protein in Association with Blood Flow Redistribution away from Peripheral Circulations in Fetal Sheep
}

\author{
DINO A. GIUSSANI, AVNESH S. THAKOR, ROSANNA FRULIO, AND DIEGO GAZZOLO \\ Department of Physiology [D.A.G., A.S.T.], University of Cambridge, Cambridge, CB2 3EG, United \\ Kingdom; Lister Institute for Preventive Medicine [D.A.G.], United Kingdom; and Department of \\ Paediatrics [R.F., D.Z.], Giannina Gaslini Children's University Hospital, 16147 Genoa, Italy and \\ Department of Fetal Maternal and Neonatal Health, G. Garibaldi Hospital, 95100 Catania, Italy
}

\section{ABSTRACT}

\begin{abstract}
We investigated in fetal sheep during late gestation the effects of acute hypoxemia on fetal plasma $S 100 \beta$ protein concentrations and how these relate to fetal redistribution of blood flow and acid-base status. Under general anesthesia, five Welsh Mountain sheep fetuses were instrumented with vascular catheters, and transit-time flow transducers were implanted around a femoral artery and an umbilical artery. At least $5 \mathrm{~d}$ after surgery, fetuses were subjected to $1 \mathrm{~h}$ of normoxia, $0.5 \mathrm{~h}$ of hypoxemia, and $1 \mathrm{~h}$ of recovery. Hypoxemia induced significant falls in fetal $\mathrm{pH}_{\mathrm{a}}$, arterial oxygen pressure, acid-base excess, and $\left[\mathrm{HCO}_{3}{ }^{-}\right]$, without alteration to arterial partial pressure of carbon dioxide. An increase in arterial blood pressure, a fall in heart rate, an increase in femoral vascular resistance, and a decrease in umbilical vascular resistance occurred in all fetuses. During hypoxemia, plasma $\mathrm{S} 100 \beta$ increased significantly and remained elevated until the end of the protocol. Within individual fetuses, plasma $\mathrm{S} 100 \beta$ correlated with femoral vascular resistance and $\mathrm{pH}$. In contrast, no relationship was found between $\mathrm{S} 100 \beta$ and
\end{abstract}

umbilical vascular resistance. This study reports for the first time that a controlled period of fetal hypoxemia with associated acidemia leads to persistent elevations in plasma $\mathrm{S} 100 \beta$ concentrations that strongly correlate with hemodynamic changes that are known to occur during fetal blood flow redistribution. These findings open up a new role for changes in fetal S100 $\beta$ concentrations as a possible early marker of fetal hypoxia with associated acidemia in perinatal medicine. (Pediatr Res 58: 179-184, 2005)
ABE, acid-base excess

\section{Abbreviations}
BP, blood pressure
CVO, combined ventricular output
IUGR, intrauterine growth restriction
$\mathbf{P a C O}_{2}$, arterial partial pressure of carbon dioxide
$\mathbf{P a O}_{2}$, arterial oxygen pressure
Sat $\mathrm{Hb}$, percentage saturation of $\mathrm{Hb}$

The $\mathrm{S} 100 \beta$ proteins are members of a multigenic family of calcium-modulated peptides characterized by a helix-loophelix structure. They were first identified as a protein fraction detectable in brain and found to be mostly of low molecular weight of $\sim 10,000 \mathrm{Da}$. They are called S100 because of their solubility in a $100 \%$ saturated solution with ammonium sulfate. In the nervous system, the protein is concentrated in glial cells, but it can also be present in specific neuron populations. Its half-life in the circulation is $\sim 1 \mathrm{~h}$, and $98 \%$ of the protein is excreted in urine (1-3).

Received August 4, 2004; accepted January 7, 2005

Correspondence: Dino A. Giussani, Ph.D., Department of Physiology, University of Cambridge, Downing Street, Cambridge CB2 3EG; e-mail. dag26@cam.ac.uk.

The work was supported by The International Journal of Experimental Pathology and The Lister Institute for Preventive Medicine. D.A.G. is a Fellow of The Lister Institute for Preventive Medicine.

DOI: 10.1203/01.PDR.0000169999.66157.C0
An elevation in the concentration of $\mathrm{S} 100 \beta$ in biologic fluids, such as cerebrospinal fluid and plasma, has been proposed to be a reliable marker of stress to the CNS (4-9). During human pregnancy, the concentration of circulating $\mathrm{S} 100 \beta$ is increased in human fetuses with intrauterine growth restriction (IUGR), in particular in those who show redistribution of blood flow toward the brain (10). This is important because redistribution of blood flow away from peripheral circulations is an established cardiovascular defense response to hypoxia and asphyxia in the fetus (11). Michetti and Gazzolo (2) reported that the expression of $S 100 \beta$ increases in biologic fluids in the fetus during complicated intrauterine conditions, at times when other clinical assessments miss the adverse diagnosis. More recently, it was also reported that infants with moderate and severe hypoxic ischemic encephalopathy after perinatal asphyxia had significantly higher serum S100 $\beta$ levels on the first 2 postnatal days relative to healthier infants (12). Thus, S100 $\beta$ may be released during hypoxia/ 
asphyxia, and, if so, measurement of its concentration may aid the early clinical diagnosis of hypoxic/ischemic stress and susceptibility to brain damage during the perinatal period. However, no study to date has reported changes in plasma concentrations of $\mathrm{S} 100 \beta$ during actual hypoxemia in the fetus and how these may correlate with cardiovascular and metabolic function in the fetus. As a first step, this study investigated the effects of acute hypoxemia on fetal plasma concentrations of $\mathrm{S} 100 \beta$ and how these relate to changes in fetal redistribution of blood flow and acid-base status, using fetal sheep surgically prepared for long-term recording.

\section{METHODS}

Surgical preparation. All procedures were performed under the UK Animals (Scientific Procedures) Act 1986 and were approved by the Ethical Review Committee of the University of Cambridge. Five Welsh Mountain sheep fetuses, between 118 and $125 \mathrm{~d}$ of gestation (term is $145 \mathrm{~d}$ ), were surgically instrumented for long-term recording using strict aseptic conditions as previously described in detail (11). In brief, food but not water was withheld from the pregnant ewes for $24 \mathrm{~h}$ before surgery. After induction with $20 \mathrm{mg} / \mathrm{kg}$ i.v. sodium thiopentone (Intraval Sodium; Merial Animal Health Ltd, Rhone Mérieux, Dublin, Ireland), general anesthesia (1.5-2.0\% halothane in 50:50 $\mathrm{O}_{2}: \mathrm{N}_{2} \mathrm{O}$ ) was maintained using positive pressure ventilation. Midline abdominal and uterine incisions were made, the fetal hind limbs were exteriorized, and on one side femoral arterial (i.d., $0.86 \mathrm{~mm}$; o.d., $1.52 \mathrm{~mm}$; Critchly Electrical Products, NSW, Australia) and venous (i.d., $0.56 \mathrm{~mm}$; o.d., 0.96 $\mathrm{mm})$ catheters were inserted. The catheter tips were advanced carefully to the ascending aorta and superior vena cava, respectively. Another catheter was anchored onto the fetal hind limb for recording of the reference amniotic pressure. In addition, transit-time flow transducers were implanted around the contralateral femoral artery ( $2 \mathrm{~S}$ with silicon flange; Transonic Systems, Ithaca, $\mathrm{NY}$ ) and one of the umbilical arteries close to the common umbilical artery, inside the fetal abdominal cavity (4SB; Transonic Systems), for continuous measurement of femoral blood flow and unilateral umbilical blood flow, respectively $(11,13)$. The uterine incisions were closed in layers, the dead space of the catheters was filled with heparinized saline ( $80 \mathrm{IU}$ heparin $/ \mathrm{ml}$ in $0.9 \% \mathrm{NaCl}$ ), and the catheter ends were plugged with sterile brass pins. The catheters and flow probe leads then were exteriorized via a keyhole incision in the maternal flank and kept inside a plastic pouch sewn onto the maternal skin.

Postoperative care. The ewes were housed in individual pens with free access to hay and water, in rooms with a 12-h dark/12-h light cycle. They were fed concentrates twice daily ( $100 \mathrm{~g}$; sheep nuts no. 6; H \& C Beart Ltd, Kings Lynn, UK). All ewes received postoperative analgesia $(10-20 \mathrm{mg} / \mathrm{kg}$ oral Phenylbutazone; Equipalozone paste; Arnolds Veterinary Products Ltd, Shropshire, UK) and antibiotics $(0.20-0.25 \mathrm{mg} / \mathrm{kg}$ i.m. Depocillin; Mycofarm, Cambridge, UK). The patency of the fetal vascular catheters was maintained by a slow continuous infusion of heparinized saline ( $80 \mathrm{IU}$ heparin/ $\mathrm{ml}$ at 0.1 $\mathrm{mL} / \mathrm{h}$ in $0.9 \% \mathrm{NaCl})$ that contained antibiotic $(1 \mathrm{mg} / \mathrm{ml}$ benzylpenicillin; Crystapen, Schering-Plough, Animal Health Division, Welwyn Garden City, UK). In addition, the fetuses received daily antibiotics $(150 \mathrm{mg} / \mathrm{kg}$ Penbritin; SmithKline Beecham Animal Health, Welwyn Garden City, Hertfordshire, UK) i.v. and into the amniotic cavity.

Experimental protocol. After at least $5 \mathrm{~d}$ of postoperative recovery, all fetuses were subjected to an experimental protocol that consisted of a $2.5-\mathrm{h}$ period divided into $1 \mathrm{~h}$ of normoxia, $0.5 \mathrm{~h}$ of hypoxemia, and $1 \mathrm{~h}$ of recovery (Fig. 1). Acute hypoxemia in the fetus was induced by maternal inhalational hypoxia. In brief, a large transparent respiratory hood was placed over the

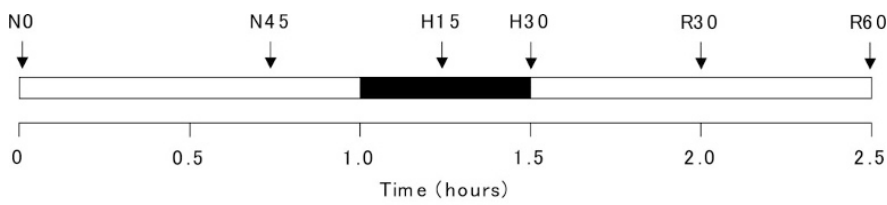
Normoxia $[1 \mathrm{~h}]$
Hypoxemia $[0.5$
Recovery $[1 \mathrm{~h}]$
h]

Figure 1. The experimental protocol consisted of a 2.5 -h period divided into $1 \mathrm{~h}$ of normoxia, $0.5 \mathrm{~h}$ of hypoxemia $(\square)$, and $1 \mathrm{~h}$ of recovery. Arrows represent time at which arterial blood samples were collected. ewes' head into which air was passed at a rate of $\sim 50 \mathrm{~L} / \mathrm{min}$ for the 1-h period of normoxia. After this control period, acute fetal hypoxemia was induced for $30 \mathrm{~min}$ by changing the concentrations of gases breathed by the ewe to $6 \% \mathrm{O}_{2}$ in $\mathrm{N}_{2}$ with small amounts of $\mathrm{CO}_{2}\left(15 \mathrm{~L} / \mathrm{min}\right.$ air:35 L/min $\mathrm{N}_{2}: 1.5-2.5 \mathrm{~L} / \mathrm{min}$ $\mathrm{CO}_{2}$ ). This mixture was designed to reduce fetal arterial oxygen pressure $\left(\mathrm{PaO}_{2}\right)$ to $\sim 10 \mathrm{~mm} \mathrm{Hg}$ while maintaining arterial partial pressure of carbon dioxide $\left(\mathrm{PaCO}_{2}\right)$. After the 0.5 -h period of hypoxemia, the ewe was returned to breathing air for the 1-h recovery period. At the end of the experimental protocol, the ewes and fetuses were killed humanely using a lethal dose of sodium pentobarbitone ( $200 \mathrm{mg} / \mathrm{kg}$ i.v. Pentoject; Animal Ltd, York, UK), and the positions of the implanted catheters and the flow probe were confirmed and the fetuses were weighed.

Measurements. During the acute hypoxemia protocol, descending aortic blood samples $(4 \mathrm{~mL})$ were taken from the fetus at set intervals (arrows) to determine plasma concentrations of $\mathrm{S} 100 \beta$, arterial blood gases, and acid-base status. Values for $\mathrm{pH}\left(\mathrm{pH}_{\mathrm{a}}\right), \mathrm{PaO}_{2}, \mathrm{PaCO}_{2}$, acid-base excess (ABE), and blood concentrations of bicarbonate $\left[\mathrm{HCO}_{3}{ }^{-}\right]$were obtained using a blood gas analyser (ABL 5; Radiometer, Copenhagen, Denmark), corrected to $39.5^{\circ} \mathrm{C}$ for fetal blood. Values for blood $\mathrm{Hb}$ concentration $[\mathrm{Hb}]$ and percentage saturation of $\mathrm{Hb}(\mathrm{Sat} \mathrm{Hb})$ with oxygen were determined using a hemoximeter (OSM2; Radiometer). The remainder of the fetal blood was transferred into $\mathrm{K}^{+}$/EDTAtreated tubes, kept on ice, and centrifuged at $4000 \mathrm{rpm}$ for $4 \mathrm{~min}$ at $4^{\circ} \mathrm{C}$. Plasma samples were stored at $-20^{\circ} \mathrm{C}$ until analysis. The endocrine analysis was completed within 2 mo of plasma collection.

Measurement of S100 $\beta$. Plasma concentrations of $S 100 \beta$ were measured in all samples by an immunoluminometric assay (Liaison Sangtec 100; AB Sangtec Medical, Bromma, Sweden). According to the manufacturer's instructions, this assay is specific for the $\beta$ subunit of the $\mathrm{S} 100$ protein as defined by the three MAb SMST 12, SMSK 25, and SMSK 28 (10). Each measurement was performed in duplicate according to the manufacturer's recommendations, and the averages were reported. The sensitivity of the assay $\left(\mathrm{B}_{0} \pm 3 \mathrm{SD}\right)$ was $0.02 \mu \mathrm{g} / \mathrm{L}$, and the intra- and interassay coefficients of variation were 5.5 and $10.1 \%$, respectively, for concentrations ranging between 0.3 and $4.2 \mu \mathrm{g} / \mathrm{L}$.

Data and statistical analyses. Calibrated mean fetal arterial blood pressure (BP; corrected for amniotic pressure) and fetal heart rate (triggered from the pulsatility in arterial BP) were recorded at 1-s intervals using computerized Data Acquisition System. Femoral vascular resistance was calculated by dividing mean corrected arterial BP by the mean femoral blood flow, and umbilical vascular resistance was calculated by dividing mean corrected arterial BP by the mean umbilical blood flow. Values for all variables are expressed as mean \pm SEM at 0 (N0) and 45 (N45) min of normoxia, 15 (H15) and 30 (H30) min of hypoxemia, and 30 (R30) and 60 (R60) min of recovery. All measured variables first were assessed for normality of distribution and then analyzed using one-way ANOVA with repeated measures (Sigma Chemical Co.-Stat; SPSS Inc., Chicago, IL) comparing the effect of time (normoxia versus hypoxemia or recovery). When a significant effect of time was indicated, the post hoc Tukey's test was used to isolate the statistical differences. In addition, the relationship between plasma concentrations of $\mathrm{S} 100 \beta$ and cardiovascular and acid-base status in all individual fetuses was assessed using the Pearson Product moment correlation. For all comparisons, statistical significance was accepted at $p<0.05$.

\section{RESULTS}

Fetal arterial blood gas and acid-base status during acute hypoxemia. Basal values for arterial blood gas and acid-base status were within the normal range for Welsh Mountain sheep fetuses at $\sim 125 \mathrm{~d}$ of gestation. In all fetuses, acute hypoxemia induced significant falls in $\mathrm{pH}_{\mathrm{a}}, \mathrm{PaO}_{2}$, Sat $\mathrm{Hb}, \mathrm{ABE}$, and $\mathrm{HCO}_{3}{ }^{-}$without any alteration to arterial $\mathrm{PaCO}_{2}$ (Table 1). During recovery, both $\mathrm{PaO}_{2}$ and $\mathrm{Sat} \mathrm{Hb}$ recovered to basal values in all fetuses. In contrast, fetal $\mathrm{pH}_{\mathrm{a}}, \mathrm{ABE}$, and $\mathrm{HCO}_{3}{ }^{-}$ remained significantly depressed from basal values until the end of the experimental protocol.

Fetal cardiovascular function during acute hypoxemia. Basal values for arterial BP, heart rate, femoral vascular resistance, and umbilical vascular resistance were similar in all fetuses and within the normal range for Welsh Mountain sheep fetuses at $\sim 125 \mathrm{~d}$ of gestation. During acute hypoxemia, there was a pronounced increase in arterial BP (from $62.5 \pm 1.7$ to $72.0 \pm 2.3 \mathrm{~mm} \mathrm{Hg}$ ), fall in heart rate (from $165 \pm 9$ to $130 \pm$ 
HYPOXIA AND S100 $\beta$ IN THE OVINE FETUS

Table 1. Fetal arterial blood gas and acid base status

\begin{tabular}{|c|c|c|c|c|c|c|}
\hline & \multicolumn{2}{|c|}{ Normoxia } & \multicolumn{2}{|c|}{ Acute Hypoxemia } & \multicolumn{2}{|c|}{ Recovery } \\
\hline & N15 & N45 & H15 & $\mathrm{H} 30$ & $\mathrm{R} 30$ & R60 \\
\hline $\mathrm{pHa}$ & $7.35 \pm 0.01$ & $7.35 \pm 0.01$ & $7.29 \pm 0.02 *$ & $7.22 \pm 0.02^{*}$ & $7.24 \pm 0.02 *$ & $7.28 \pm 0.02 *$ \\
\hline $\mathrm{Pa}, \mathrm{O} 2(\mathrm{mmHg})$ & $20.0 \pm 0.7$ & $19.8 \pm 0.6$ & $9.2 \pm 0.5^{*}$ & $9.8 \pm 1.0^{*}$ & $19.0 \pm 2.2$ & $18.4 \pm 0.5$ \\
\hline Sat $\mathrm{Hb}(\%)$ & $49.9 \pm 4.0$ & $51.5 \pm 4.1$ & $16.1 \pm 1.1^{*}$ & $16.6 \pm 1.8^{*}$ & $42.8 \pm 5.2$ & $40.6 \pm 2.8$ \\
\hline $\mathrm{ABE}\left(\right.$ mequiv $1^{-1}$ ) & $3.2 \pm 0.7$ & $3.4 \pm 0.7$ & $-2.0 \pm 1.3^{*}$ & $-6.8 \pm 1.4^{*}$ & $-5.6 \pm 1.5^{*}$ & $-3.0 \pm 1.1^{*}$ \\
\hline
\end{tabular}

* Values represent the mean \pm S.E.M. of $n=5$ at 15 (N15) and 45 (N45) min of normoxia, at 15 (H15) and 30 (H30) min of hypoxaemia, and at 30 (R30) and 60 (R60) min of recovery. Significant differences: $* p<0.05$ for normoxia vs. hypoxemia or recovery. $\mathrm{pH}_{\mathrm{ar}}$ arterial $\mathrm{pH} ; \mathrm{P}_{\mathrm{a}} \mathrm{CO}_{2}$, arterial partial pressure of $\mathrm{CO}_{2} ; \mathrm{PO}_{2}$, arterial partial pressure of $\mathrm{O}_{2}$; Sat $\mathrm{Hb}$, percentage saturation of oxygen with haemoglobin; $\mathrm{ABE}$, acid base excess; [HCO3], blood concentration of bicarbonate ions.

13 beats/min), increase in femoral vascular resistance (from 1.69 \pm 0.15 to $\left.12.04 \pm 2.58 \mathrm{~mm} \mathrm{Hg} \cdot \mathrm{ml}^{-1} \cdot \mathrm{min}^{-1}\right)$, and a decrease in umbilical vascular resistance (from $0.50 \pm 0.04$ to $0.38 \pm 0.04$ $\mathrm{mm} \mathrm{Hg} \cdot \mathrm{ml}^{-1} \cdot \mathrm{min}^{-1}$ ) in all fetuses (all $p<0.05$; Fig. 2). Whereas heart rate and femoral vascular resistance returned toward basal values during recovery, arterial BP and umbilical vascular resistance remained altered from baseline $(p<0.05)$.

Plasma S100ß during acute hypoxemia. Basal fetal plasma S100 $\beta$ concentrations averaged $9.6 \pm 2.8 \mu \mathrm{g} / \mathrm{L}$. During acute hypoxemia, $\mathrm{S} 100 \beta$ concentrations increased significantly by $24.9 \pm 2.9 \%$ (Fig. 3). This elevation in $\mathrm{S} 100 \beta$ concentration

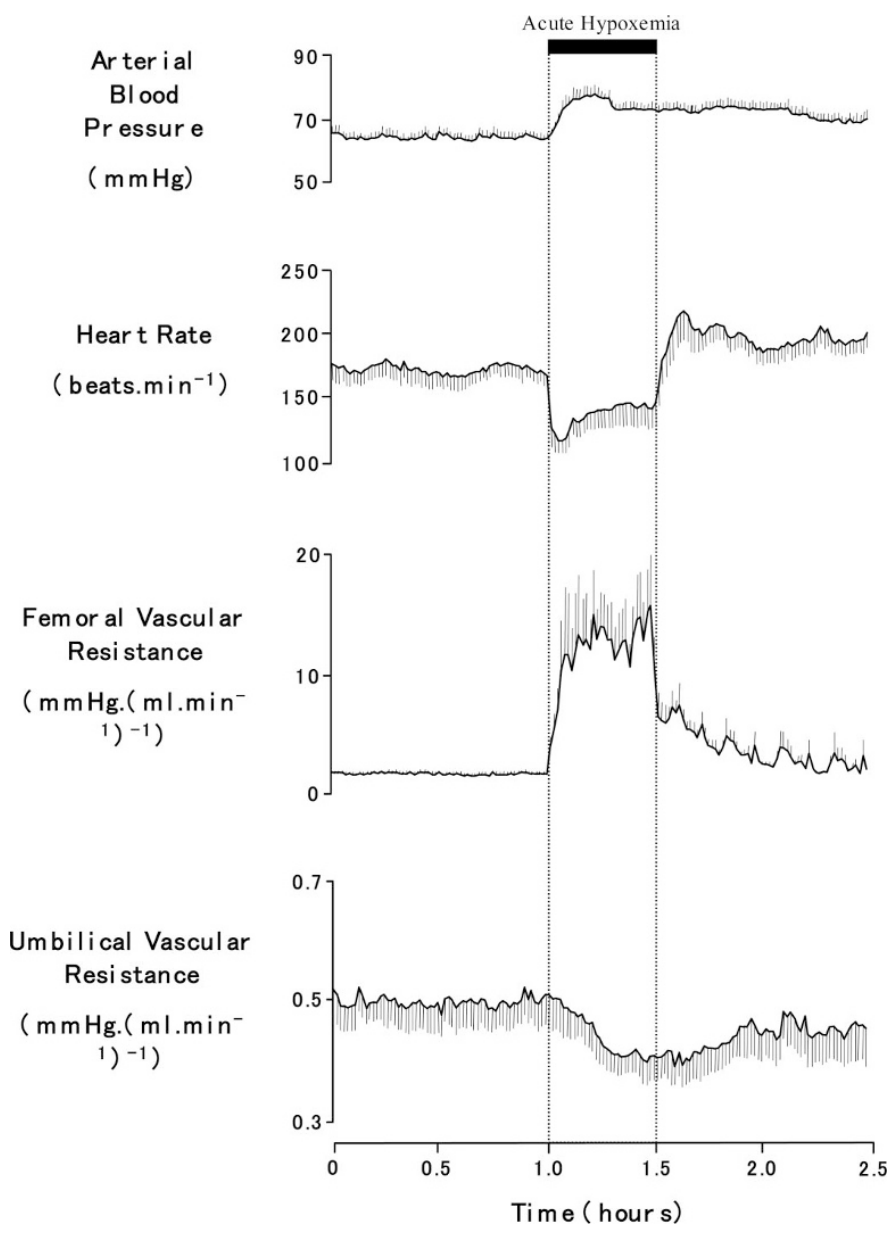

Figure 2. Cardiovascular responses to acute hypoxemia in the sheep fetus. Values are mean \pm SEM of $n=5$ calculated every minute for arterial BP, heart rate, and femoral and umbilical vascular resistance during $1 \mathrm{~h}$ of normoxia, $0.5 \mathrm{~h}$ of hypoxemia (box), and $1 \mathrm{~h}$ of recovery.

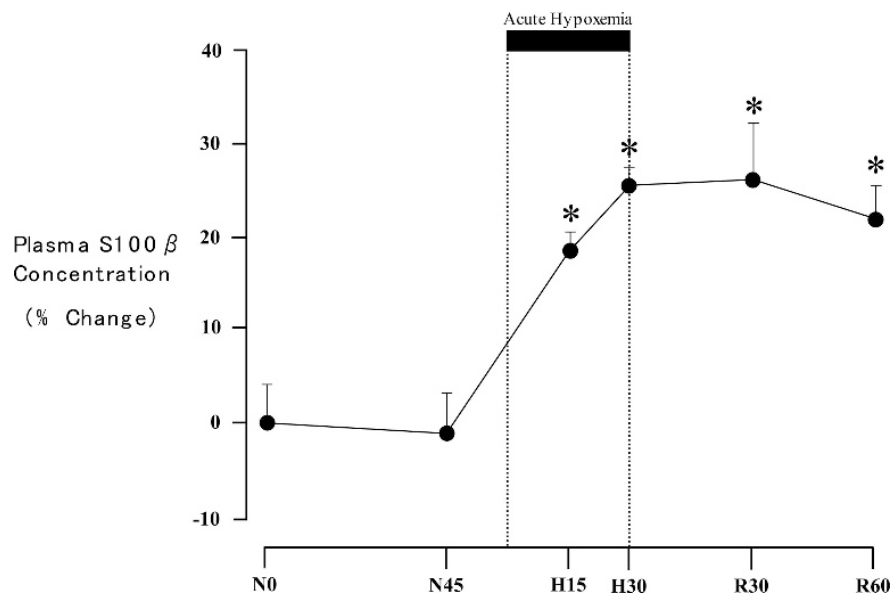

Figure 3. Plasma $S 100 \beta$ concentrations in response to acute hypoxemia in the sheep fetus. Values are mean \pm SEM of $n=5$ of the percentage change from baseline during the acute hypoxemic protocol. ${ }^{*} p<0.05$ for normoxia $v s$ hypoxemia or recovery.

persisted until the end of the experimental protocol, with values remaining significantly elevated from baseline by 21.9 $\pm 4.1 \%$.

Relation among plasma S100ß, cardiovascular function, and acid-base status in the fetus during acute hypoxemia. Correlation analysis for all individual fetuses during all values obtained during normoxic and hypoxemic conditions between the percentage changes in $\mathrm{S} 100 \beta$ concentration and femoral vascular resistance revealed a significant positive relationship ( $r=0.71, n=20, p<0.001$; Fig. 4). In marked contrast, no relationship was found between the percentage change in
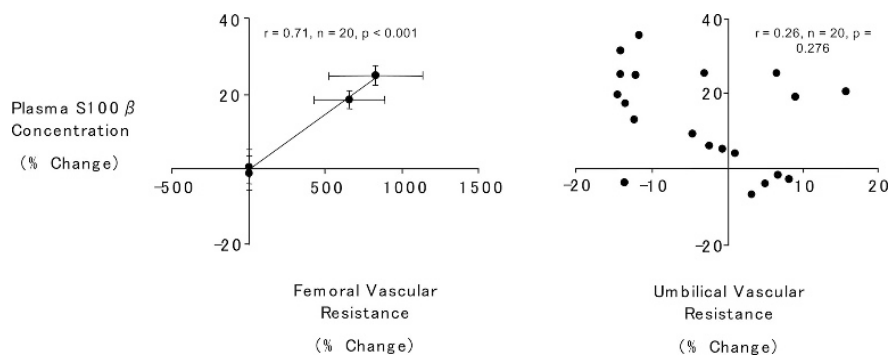

Figure 4. Plasma $\mathrm{S} 100 \beta$ concentrations and hemodynamic changes in the sheep fetus. The data show the association between the percentage change in plasma $\mathrm{S} 100 \beta$ concentration and the percentage change in femoral and umbilical vascular resistance. R, Pearson product moment correlation coefficient. Data points during normoxia and hypoxemia $(n=20)$ from all animals $(n=$ 5) were correlated. 
S100 $\beta$ concentration and umbilical vascular resistance $(r=$ $0.26, n=20, p=0.27$; Fig. 4). Correlation analyses between the plasma $\mathrm{S} 100 \beta$ concentration and fetal acid-base status was measured by assessing the relationship between the percentage changes in plasma $\mathrm{S} 100 \beta$ concentration and the percentage changes in $\mathrm{pH}, \mathrm{ABE}$, and $\left[\mathrm{HCO}_{3}{ }^{-}\right]$during normoxic and hypoxemic conditions in all individual fetuses. The analysis revealed significant negative relationships between $\mathrm{S} 100 \beta$ and $\mathrm{pH}, \mathrm{ABE}$, and $\left[\mathrm{HCO}_{3}{ }^{-}\right]$(Fig. 5).
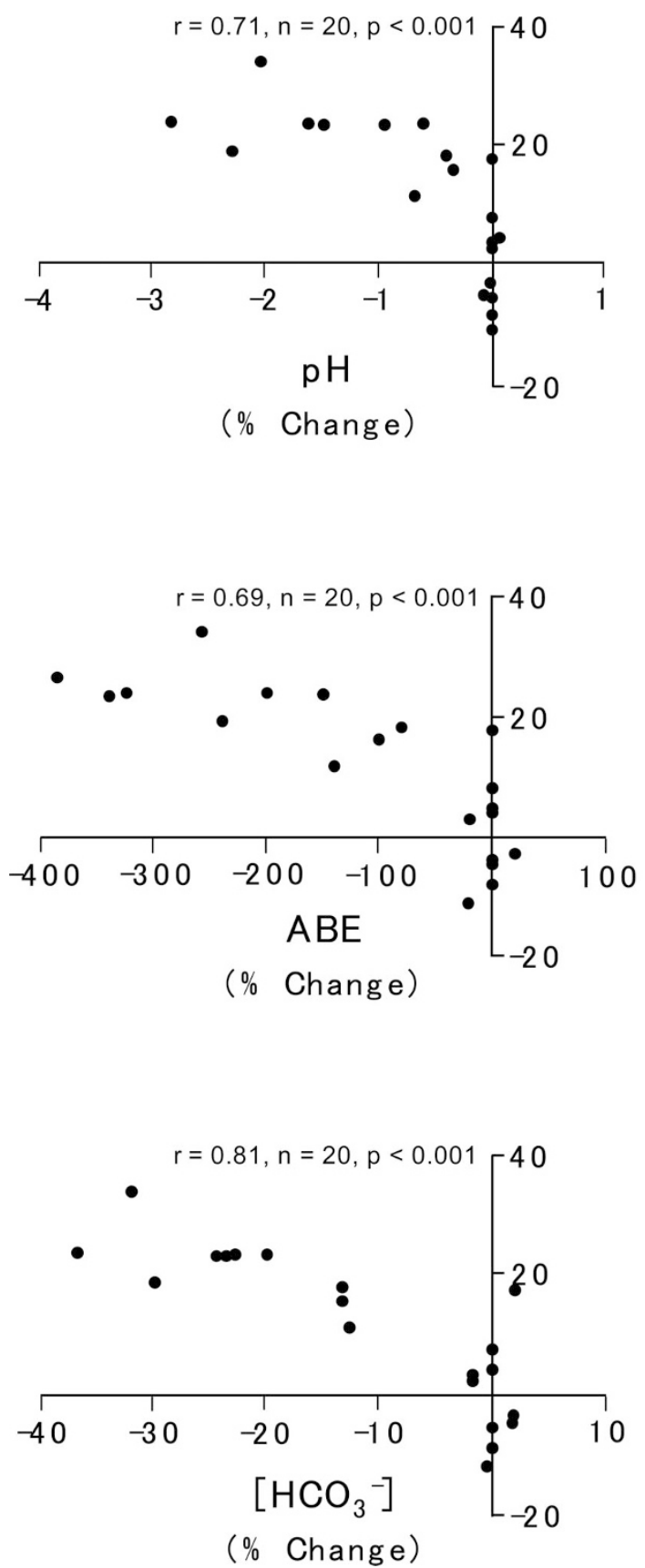

Figure 5. Plasma S100 $\beta$ concentrations and changes in acid-base status in the sheep fetus. The data show the association between the percentage change in plasma $\mathrm{S} 100 \beta$ concentration and the percentage change in $\mathrm{pH}, \mathrm{ABE}$, and blood concentrations of bicarbonate ions in all individual sheep fetuses during acute hypoxemia. Data points during normoxia and hypoxemia $(n=20)$ from all animals $(n=5)$ were correlated.

\section{DISCUSSION}

For decades, clinical tools for fetal surveillance during pregnancy have relied on fetal heart rate monitoring and Doppler blood flow velocimetry. Since the introduction of these clinical tools, surprisingly, no additional techniques have been implemented routinely into perinatal clinical practice. The protein $S 100 \beta$ has been suggested to be a marker of stress to the CNS during the adult, newborn, and fetal periods (2-10). Therefore, an early detection of elevations in $\mathrm{S} 100 \beta$ may provide the obstetrician with an additional clinical tool for detecting episodes of fetal distress. However, whether S100 $\beta$ is a marker of fetal distress of the type that is associated with brain damage, a marker of fetal hypoxia, or a marker of fetal acidemia has not been addressed to date. Here, we report that a controlled period of fetal hypoxemia in chronically instrumented fetal sheep in late gestation leads to significant elevations in plasma concentrations of $\mathrm{S} 100 \beta$. The increase in the concentration of the protein during hypoxemia is rapid in onset and is sustained past $60 \mathrm{~min}$ after the end of the hypoxemic challenge. Furthermore, values for changes in $\mathrm{S} 100 \beta$ concentrations in all individual fetuses were significantly related with hemodynamic and biochemical variables currently measured in clinical obstetric practice for the early detection of perinatal hypoxia and/or asphyxia. Specifically, changes in $\mathrm{S} 100 \beta$ concentrations were positively related with hemodynamic changes indicative of redistribution of blood flow during fetal hypoxemia and negatively related with changes in fetal $\mathrm{pH}, \mathrm{ABE}$, and blood concentrations of bicarbonate, indicative of acidemia.

In the experimental situation, such as in the ovine model, the fetal cardiovascular defense to an episode of acute hypoxemia involves transient bradycardia, a gradual increase in arterial $\mathrm{BP}$, and redistribution of the fetal combined ventricular output (CVO) away from peripheral circulations toward the adrenal, myocardial, cerebral, and umbilical circulations $(11,14,15)$. The redistribution of the fetal CVO is mediated via vasodilation in the essential circulations and pronounced vasoconstriction in the periphery (14-16). An established index of the fetal peripheral vasoconstrictor response contributing to redistribution of the fetal CVO during hypoxemia is an increase in femoral vascular resistance $(11,14)$. The mechanisms that mediate peripheral vasoconstriction during acute hypoxemia include well-established neural, endocrine, and local components $(14-16)$. The initial femoral vasoconstriction is triggered by a carotid chemoreflex and is mediated via $\alpha$-adrenergic sympathetic efferent pathways (11). As the episode of hypoxemia progresses, endocrine vasoconstrictors, such as catecholamines, are released into the fetal circulation (17), which maintain the peripheral vasoconstrictor response to acute hypoxemia. Furthermore, it has recently become appreciated that the peripheral vasoconstrictor response to acute hypoxemia may also involve local components $(18,19)$ and that the peripheral vasomotor response to acute hypoxemia may represent the balance between neural and endocrine constrictor influences and local vasodilator actions of nitric oxide (20). In the present study, the fetal cardiovascular responses to hypoxemia were typical of fetal sheep at this stage of gestation $(11,14)$. Furthermore, the increase in femoral vascular resistance 
plasma correlated significantly with elevations in the plasma concentrations of S100 $\beta$ during acute hypoxemia. In contrast, no relationship was obtained between changes in $\mathrm{S} 100 \beta$ and changes in umbilical vascular resistance. In human clinical practice, redistribution of blood flow away from peripheral circulations toward essential vascular beds in the fetus is assessed by Doppler blood flow velocimetry. Typically in obstetric medicine, an increase in the ratio of the resistance indices in central circulations (e.g. middle cerebral artery) to those in peripheral circulations (descending aorta or femoral arteries) is representative of the "brain-sparing effect," redistributing the fetal CVO in favor of the brain at the expense of the fetal trunk (21). A previous clinical study in our laboratory reported that in human pregnancies with IUGR, the levels of $\mathrm{S} 100 \beta$ in cord blood were negatively correlated with a decrease in the Doppler pulsatility index in the middle cerebral arteries (10). Combined, therefore, our experimental measurements in fetal sheep and our clinical observations in human pregnancies with IUGR convincingly support an association between elevations in $\mathrm{S} 100 \beta$ and redistribution of blood flow toward the cerebral circulations during hypoxemia in the fetus. It thus follows that $\mathrm{S} 100 \beta$ cannot be elevated solely during conditions of cerebral ischemia and, hence, cerebral damage, but it is better related to fetal hypoxic stress, which leads to redistribution of blood flow by triggering a chemoreflex response. As such, detection of elevations in $\mathrm{S} 100 \beta$ may better serve the obstetrician as an early clinical marker of fetal hypoxia, particularly in combination with evidence of redistribution of blood flow, which if persistent may result in fetal brain damage, rather than as a marker of fetal brain damage per $s e$. In this context, it was reported previously that persistent elevations in $\mathrm{S} 100 \beta$ in the micromolar range can be neurotoxic and lead to apoptosis and neuronal cell death (2,22). However, it is fully acknowledged that in human clinical practice, cordocentesis will be indicated only in pregnancies that already are known to be complicated. Amniocentesis may offer a more plausible option. Assays from cord blood are clearly possible but unlikely to change management, being retrospective.

In the present article, evidence is also provided that elevations in the protein concentrations of $\mathrm{S} 100 \beta$ in the fetal circulation are related not only to fetal distress in terms of fetal hypoxia but also to falls in $\mathrm{pH}, \mathrm{ABE}$, and bicarbonate concentrations, measures that are consistent with fetal metabolic acidosis. The study suggests that elevations in $\mathrm{S} 100 \beta$ together with indices of redistribution of blood flow are indicative of fetal hypoxic stress, that elevations in $\mathrm{S} 100 \beta$ with falls in $\mathrm{pH}$, $\mathrm{ABE}$, and bicarbonate are indicative of fetal acidemic stress, and that both situations are not mutually exclusive.

The source of changes in $S 100 \beta$ in the fetal circulation during and after the acute hypoxemic insult in the current study is unclear. One possibility is that changes in blood-brain barrier permeability as a result of fetal hypoxia itself or increased cerebral perfusion secondary to redistribution of blood flow may promote leakage of the protein from the CNS into the systemic circulation $(23,24)$. Alternatively, S100 $\beta$ may be released from the placenta during hypoxemic conditions. In the human, $\mathrm{S} 100 \beta$ has been localized in villous and intermediate trophoblast cells of the normal placenta at different stages of gestation (25). However, reports on changes in placental $\mathrm{S} 100 \beta$ during adverse intrauterine conditions are inconclusive and contradicting. Whereas $\mathrm{S} 100 \beta$ has been detected in pregnancies that re complicated by IUGR and preeclampsia (26), other studies did not reveal appreciable differences in $\mathrm{S} 100 \beta$ expression between uncomplicated pregnancies and those with IUGR (10).

\section{CONCLUSION}

In conclusion, this study reports for the first time that a controlled period of fetal hypoxemia with associated acidemia leads to persistent elevations in plasma S100 $\beta$ concentrations that strongly correlate with hemodynamic changes that are known to occur during fetal blood flow redistribution. These findings provide the first step in relating fetal plasma $\mathrm{S} 100 \beta$ concentrations to actual fetal hypoxia and fetal acidemia. Future research directions should advance on these findings, creating experimental models that mimic the human clinical situation, relating both fetal plasma and amniotic fluid concentrations of the protein with fetal hemodynamic variables under conditions of chronic hypoxemia, with and without developed acidemia.

Acknowledgments. We are grateful to Paul Hughes and Sue Nicholls for the care of the animals.

\section{REFERENCES}

1. Heizmann CW 1999 Calcium-binding proteins in the central nervous system. Neurochem Res 24:1097-1100

2. Michetti F, Gazzolo D 2002 S100B protein in biological fluids: a tool in perinatal medicine. Clin Chem 48:2097-2104

3. Jonsson H, Johnsson P, Hoglund P, Alling C, Blomquist S 2000 Elimination of S100B and renal function after cardiac surgery. J Cardiothorac Vasc Anesth 14:698-701

4. Michetti F, Massaro A, Murazio M 1979 The nervous system-specific S-100 antigen in cerebrospinal fluid of multiple sclerosis patients. Neurosci Lett 11:71-75

5. Michetti F, Massaro A, Russo G, Rigon G 1980 The S-100 antigen in cerebrospinal fluid as a possible index of cell injury in the nervous system. J Neurol Sci 44:259-263

6. Johnsson P, Lundquist C, Lindgren A, Ferencz I, Alling C, Stahl E 1995 Cerebral complications after cardiac surgery assessed by S100 and NSE levels in blood. J Cardiothorac Vasc Anesth 9:694-699

7. Persson L, Hardemark HG, Gustafsson J, Rundstrom G, Mendel-Hartvig I, Esscher T, Pahlman S 1987 S-100 protein and neuron-specific enolase in cerebrospinal fluid and serum: markers of cell damage in human central nervous system. Stroke 18:911-918

8. Gazzolo D, Vinesi P, Geloso MC, Marcelletti CF, Iorio FS, Marianeschi SM, Michetti F 1998 S100 blood concentrations in children subjected to cardiopulmonary by-pass. Clin Chem 44:1058-1060

9. Gazzolo D, Di Iorio R, Marinoni E, Masetti P, Serra G, Giovannini L, Michetti F 2002 S100B Protein is increased in asphyxiated term infants developing intraventricular hemorrhage. Crit Care Med 30:1356-1360

10. Gazzolo D, Marinoni E, Di Iorio R, Lituania M, Bruschettini PL, Michetti F 2002 Circulating S100B protein is increased in intrauterine growth-retarded fetuses. Pediatr Res 51:215-219

11. Giussani DA, Spencer JA, Moore PJ, Bennet L, Hanson MA 1993 Afferent and efferent components of the cardiovascular reflex responses to acute hypoxia in term fetal sheep. J Physiol 461:431-449

12. Thorngren-Jerneck K, Alling C, Herbst A, Amer-Wahlin I, Marsal K 2004 S100 protein in serum as a prognostic marker for cerebral injury in term newborn infants with hypoxic ischemic encephalopathy. Pediatr Res 55:406-412

13. Gardner DS, Giussani DA 2003 Enhanced umbilical blood flow during acute hypoxemia after chronic umbilical cord compression: a role for nitric oxide. Circulation 108:331-335

14. Giussani DA, Spencer JA, Hanson MA 1994 Fetal cardiovascular reflex responses to hypoxaemia. Fetal Matern Med Rev 6:17-37

15. Rudolph AM 1984 The fetal circulation and its response to stress. J Dev Physiol 6:11-19

16. van Bel F, Sola A, Roman C, Rudolph AM 1995 Role of nitric oxide in the regulation of the cerebral circulation in the lamb fetus during normoxemia and hypoxemia. Biol Neonate 68:200-210 
17. Jones CT, Robinson RO 1975 Plasma catecholamines in foetal and adult sheep. J Physiol 248:15-33

18. Green LR, Bennet L, Hanson MA 1996 The role of nitric oxide synthesis in cardiovascular responses to acute hypoxia in the late gestation sheep fetus. J Physio 497:271-277

19. Harris AP, Helou S, Gleason CA, Traystman RJ, Koehler RC 2001 Fetal cerebral and peripheral circulatory responses to hypoxia after nitric oxide synthase inhibition. Am J Physiol 281:R381-R390

20. Morrison S, Gardner DS, Fletcher AJ, Bloomfield MR, Giussani DA 2003 Enhanced nitric oxide activity offsets peripheral vasoconstriction during acute hypoxaemia via chemoreflex and adrenomedullary actions in the sheep fetus. J Physiol 547:283-391

21. Akalin-Sel T, Campbell S 1992 Understanding the pathophysiology of intra-uterine growth retardation: the role of the 'lower limb reflex' in redistribution of blood flow. Eur J Obstet Gynecol Reprod Biol 23:79-86
22. Hu J, Ferreira A, Van Eldik LJ 1997 S100 $\beta$ induces neuronal cell death through nitric oxide release from astrocytes. J Neurochem 69:2294-2301

23. Wigglesworth JS, Pape KE 1978 An integrated model for haemorrhagic and ischaemic lesions in the newborn brain. Early Hum Dev 2:179-199

24. Gazzolo D, Marinoni E, Di Iorio R, Bruschettini M, Kornacka M, Lituania M, Majewska U, Serra G, Michetti F 2004 Urinary S100B protein measurements: a tool for the early identification of hypoxic-ischemic encephalopathy in asphyxiated fullterm infants. Crit Care Med 32:131-136

25. Marinoni E, Di Iorio R, Gazzolo D, Lucchini C, Michetti F, Corvino V, Cosmi EV 2002 Ontogenic localization and distribution of $\mathrm{S}-100 \beta$ protein in human placental tissues. Obstet Gynecol 99:1093-1099

26. Wijnberger LD, Nikkels PG, van Dongen AJ, Noorlander CW, Mulder EJ, Schrama LH, Visser GH 2002 Expression in the placenta of neuronal markers for perinatal brain damage. Pediatr Res 51:492-496 